\title{
TET1 exerts its anti-tumor functions via demethylating DACT2 and SFRP2 to antagonize Wnt/ $\beta$-catenin signaling pathway in nasopharyngeal carcinoma cells
}

Jiangxia Fan ${ }^{\dagger}$, Yan Zhang ${ }^{\dagger}$, Junhao Mu, Xiaoqian He, Bianfei Shao, Dishu Zhou, Weiyan Peng, Jun Tang, Yu Jiang, Guosheng Ren and Tingxiu Xiang*

\begin{abstract}
Background: TET1 is a tumor suppressor gene (TSG) that codes for ten-eleven translocation methyl cytosine dioxygenase1 (TET1) catalyzing the conversion of 5-methylcytosine to 5-hydroxy methyl cytosine as a first step of TSG demethylation. Its hypermethylation has been associated with cancer pathogenesis. However, whether TET1 plays any role in nasopharyngeal carcinoma (NPC) remains unclear. This study investigated the expression and methylation of TET1 in NPC and confirmed its role and mechanism as a TSG.

Results: TET1 expression was downregulated in NPC tissues compared with nasal septum deviation tissues. Demethylation of TET1 in HONE1 and HNE1 cells restored its expression with downregulated methylation, implying that TET1 was silenced by promoter hypermethylation. Ectopic expression of TET1 suppressed the growth of NPC cells, induced apoptosis, arrested cell division in G0/G1 phase, and inhibited cell migration and invasion, confirming TET1 TSG activity. TET1 decreased the expression of nuclear $\beta$-catenin and downstream target genes. Furthermore, TET1 could cause Wnt antagonists (DACT2, SFRP2) promoter demethylation and restore its expression in NPC cells.

Conclusions: Collectively, we conclude that TET1 exerts its anti-tumor functions in NPC cells by suppressing Wnt/ $\beta$ catenin signaling via demethylation of Wht antagonists (DACT2 and SFRP2).
\end{abstract}

Keywords: TET1, Tumor suppressor, Nasopharyngeal carcinoma, Wnt pathway, Demethylation

\section{Background}

The worldwide incidence and mortality of nasopharyngeal carcinoma (NPC) is very low, but it is high in southern China $[1,2]$. Radiation therapy is currently the primary treatment in the earlier stage, and combined with chemoradiotherapy in the late stage, but distant metastasis and recurrence are frequent $[3,4]$. As NPC is regulated by genetic and epigenetic factors $[5,6]$, biomarkers would help to improve treatment and outcomes. In NPC, many tumor suppressor genes (TSGs), such as $P C D H 20$ [7], WIF1 [7, 8], RASSF1 [9], ADAMTS18 [10], PTPRG [11], CDH4 [12], CDH11 [13], SOX11 [14], and DACT2 [15],

\footnotetext{
*Correspondence: larissaxiang@163.com

${ }^{\dagger}$ Jiangxia Fan and Yan Zhang contributed equally to this work.

Chongqing Key Laboratory of Molecular Oncology and Epigenetics, the First

Affiliated Hospital of Chongqing Medical University, Chongqing, China
}

are silenced by hyper-methylation. Some are associated with $\mathrm{Wnt} / \beta$-catenin pathway activation $[7,8,13,15,16]$.

The ten-eleven translocation (TET) proteins, TET1, TET2, and TET3 are highly active DNA cytosine oxygenases that maintain TSGs in an unmethylated state by conversion of 5-methyl cytosine $(5 \mathrm{mC})$ to 5 -hydroxymethyl cytosine $(5 \mathrm{hmC})$ or by competition with DNA methyltransferases resulting in passive demethylation $[17,18]$. Its $\mathrm{C}$-terminal region is the catalytic domain, and the $\mathrm{N}$-terminal region has a conserved CXXC domain [19], which identifies cytosine. TET1 contains three nuclear localization signals, indicating potential activity in the nucleus [20]. The TET1 gene is located at chromosome $10 \mathrm{q} 21.3$, and it was first described in a patient with acute myeloid leukemia associated with a chromosome translocation $[21,22]$. TET1 is active as a TSG in breast

(C) The Author(s). 2018 Open Access This article is distributed under the terms of the Creative Commons Attribution 4.0 International License (http://creativecommons.org/licenses/by/4.0/), which permits unrestricted use, distribution, and 
[23], colon [24], gastric [25], prostate [26], hepatocellular [27], and renal carcinoma [28]. Its hyper-methylation has been associated with cancer pathogenesis. Li et al. showed that TET1, TET2, and TET3 are highly expressed in normal tissues, but only TET1 is downregulated in nasopharyngeal carcinoma cells [29]. Therefore, this study investigated the expression and methylation of TET1 in NPC and confirmed its role as a TSG. TET1 catalyzed several TSG demethylations to renew their expression, and suppressed Wnt/ $\beta$-catenin pathway. Thus, TET1 and its candidate target genes all are potential NPC biomarkers.

\section{Methods}

\section{Tumor cell lines and tumor samples}

The HNE1 and HONE1 nasopharyngeal carcinoma cell lines were obtained from Prof. Qian Tao, the Chinese University of Hong Kong, Hong Kong, China. The cells were maintained in RPMI 1640 (Gibco BRL, MD, USA) supplemented with $10 \%$ fetal bovine serum (FBS; PAA Laboratories, Linz, Austria), $100 \mathrm{U} / \mathrm{ml}$ penicillin (Gibco-BRL), and $100 \mu \mathrm{g} / \mathrm{ml}$ streptomycin (Gibco-BRL) at $37^{\circ} \mathrm{C}$ in humidified air with $5 \% \mathrm{CO}_{2}$. Normal nasal tissues were obtained from the patients of nasal septum deviation (NSD); surgical margin tissues and nasopharyngeal carcinoma tissues were obtained from surgical patients treated at the Otolaryngology Surgery Department of the First Affiliated Hospital of Chongqing Medical University.

\section{DNA and RNA extraction}

Genomic DNA was extracted from cell lines and NPC tissues using a QIA amp DNA Mini Kit following the manufacturer's instructions (Qiagen, Hilden, Germany). Total RNA was extracted from cell lines and NPC tissues using TRIzol reagent (Invitrogen, Carlsbad, CA, USA). Total DNA and RNA were quantified by gel electrophoresis. Samples were stored at $-80{ }^{\circ} \mathrm{C}$ until used.

5-aza-2'-deoxycytidine (Aza) and (trichostatin A) TSA treatments Aza and TSA treatments were performed as described previously [30, 31]. HNE1 and HONE1 cells were treated with final concentration $10 \mu \mathrm{mol} / \mathrm{l}$ Aza (Sigma-Aldrich, Steinheim, Germany) for 3 days with or without $100 \mathrm{nmol} / \mathrm{l}$ TSA (Sigma-Aldrich) for another $24 \mathrm{~h}$.

\section{Semi-quantitative RT-PCR and quantitative real-time PCR (qRT-PCR)}

Semi-quantitative RT-PCR was performed with a $10 \mu \mathrm{l}$ reaction mixture containing $2 \mu \mathrm{l} \mathrm{cDNA}$ using Go-taq (Promega, Madison, WI, USA). $\beta$-actin was amplified as the control and 32 cycles for TET1 and target genes. The primer sequences are listed in Table 1. qPCR of
TET1 in NPC tissues and cell lines were normalized against $\beta$-actin. qRT-PCR was using SYBR $^{\circ}$ Green PCR Master Mix (Thermo Fisher Scientific, Hong Kong, China) in the HT7500 system (Applied Biosystems).

Bisulfite genomic sequencing and methylation-specific PCR Bisulfite modification of DNA and methylation-specific PCR (MSP) were performed as previously described [32, 33]. Bisulfite-treated DNA was amplified with primers specific for methylated or non-methylated TET1. For bisulfite genomic sequencing (BGS), bisulfite-treated DNA was amplified using the primers shown in Table 1. The PCR products were cloned into eight to ten randomly chosen colonies using pCR4-Topo vector (Invitrogen Corporation, Carlsbad, CA) and then sequenced.

\section{Construction of plasmids and stable cell lines}

The TET1 plasmid contains the catalytic domain (CD) including the Cys-rich and DSBH regions. Both pcDNA3.1-Flag-HA-TET1-CD-His (pcDNA3.1-TET1-CD) plasmid with the $\mathrm{CD}$ regions (enzymatically active) and pcDNA3.1-Flag-HA-TET1-CD-mut-His (pcDNA3.1-TET1 -CD-mut) plasmid with two amino acid substitutions in $\mathrm{CD}$ regions (enzymatically inactive) were gifts from Prof. Qian Tao (Chinese University of Hong Kong, Hong Kong, China) [29]. pN3myc-TET1-CD (pcDNA3.1-myc-TET1) was constructed by EcoRI and XbaI enzyme digestion pcDNA3.1-Flag-HA-TET1-CD-His and subcloned into pcNDA3.1-N3myc plasmids, which was validated by RT-PCR and sequencing. And pTopflash and pFopflash were used in our previous work [34].

pcDNA3.1 vector and pcDNA3.1-TET1-CD, pcDNA3.1-TET1-CD-mut were transfected into cells using Lipofectamine2000 (Invitrogen Corporation, Carlsbad, CA, USA) according to the manufacturer's protocol. Stable cells were confirmed by RT-PCR and Western blot.

\section{Dot-blot analysis}

Genomic DNA was purified, sonicated, denatured in $2 \times$ DNA denaturing buffer, and incubated at $95{ }^{\circ} \mathrm{C}$ for $10 \mathrm{~min}$ before spotting onto polyvinylidene difluoride (PVDF; Bio-Rad, Hercules, CA, USA) membranes. Equal amounts of DNA were allowed to spotting onto the membranes, which were then dried at room temperature. After UV cross-linking at $1200 \mathrm{~J} / \mathrm{m}^{2}$ and $2 \mathrm{~h}$ at $60{ }^{\circ} \mathrm{C}$ in incubator, membranes were blocked with $5 \%$ low-fat milk for $1 \mathrm{~h}$ at room temperature and incubated with primary antibodies against 5-hmC (1:5000; \#39769; active motif), $5 \mathrm{mC}$ (1:1000; \#28692;Cell Signaling Technology) overnight at $4{ }^{\circ} \mathrm{C}$ with gentle agitation. Membranes were incubated with secondary antibodies and read to detect DNA using 
Table 1 List of primers used in this study

\begin{tabular}{|c|c|c|c|c|c|}
\hline$P C R$ & Primer & Sequence $\left(5^{\prime}-3^{\prime}\right)$ & Product size (bp) & PCR Cycles & Annealing temperature $\left({ }^{\circ} \mathrm{C}\right)$ \\
\hline \multirow[t]{4}{*}{ RT-PCR } & TET1F & AGGACCAAGTGTTGCTGCTGT & 219 & 32 & 55 \\
\hline & TET1R & ATCACAGCAGTTGGACAGTGG & & & \\
\hline & $\beta$-actinf & TCCTGTGGCATCCACGAAACT & 315 & 23 & 55 \\
\hline & $\beta$-actinR & GAAGCATTTGCGGTGGACGAT & & & \\
\hline \multirow[t]{32}{*}{ qRT-PCR } & DKK1F & CTGCATGCGTCACGCTATGT & 161 & & 60 \\
\hline & DKK1R & AGGTGGTTCTTCTGGAATAC & & & \\
\hline & $D K K 2 F$ & ACCCGCTGCAATAATGGAATC & 99 & & 60 \\
\hline & $D K K 2 R$ & ATGGTTGCGATCTCTATGCCG & & & \\
\hline & Snail1F & GAGGCGGTGGCAGACTAG & 159 & & 60 \\
\hline & SnaillR & GACACATCGGTCAGACCAG & & & \\
\hline & DKK3F & CACCCTCAATGAGATGTTCC & 161 & & 60 \\
\hline & $D K K 3 R$ & TGGTCTCATTGTGATAGCTG & & & \\
\hline & DACT1F & CTGGAGGAGAAGTTCTTGGA & 161 & & 60 \\
\hline & DACT1R & TCCAGGTGCTCTTCAGATGT & & & \\
\hline & $D A C T 2 F$ & AGCCGTGGGGCACATTCTG & 173 & & 60 \\
\hline & $D A C T 2 R$ & CCAGGTCCTGCCGATACTTG & & & \\
\hline & SFRPIF & ACGAGTTGAAATCTGAGGCCATC & 197 & & 60 \\
\hline & SFRPIR & ACAGTCAGCCCCATTCTTCAG & & & \\
\hline & SFRP2F & ATCCTGGAGACCAAGAGCAAGAC & 142 & & 60 \\
\hline & SFRP2R & TGACCAGATAGGGCGCGTTGATG & & & \\
\hline & WNT5BF & AAATGCCACGGCGTCTCG & 163 & & 60 \\
\hline & WNT5BR & GGGTGAAGCGGCTGTTGA & & & \\
\hline & WNT3F & ACGAGAACTCCCCCAACTTT & 170 & & 60 \\
\hline & WNT3R & GATGCAGTGGCATTITTCCT & & & \\
\hline & WNT5AF1 & CGGTGTACAACCTGGCTGATG & 101 & & 60 \\
\hline & WNT5AR1 & CACCTTGCGGAAGTCTGCC & & & \\
\hline & WNT7AF & CTGGAACTGCTCTGCACTGGGA & 129 & & 60 \\
\hline & WNT7AR & GTACAGGCAGCTGTGATGGCGT & & & \\
\hline & WNT7BF & TTTGGCGTCCTCTACGTGAAG & 145 & & 60 \\
\hline & WNT7BR & CCCCGATCACAATGATGGCA & & & \\
\hline & EcadF & TACACTGCCCAGGAGCCAGA & 103 & & 60 \\
\hline & EcadR & TGGCACCAGTGTCCGGATTA & & & \\
\hline & NcadF & CGAATGGATGAAAGACCCATCC & 174 & & 60 \\
\hline & NcadR & GGAGCCACTGCCTTCATAGTCAA & & & \\
\hline & $\beta$-actinF1 & GTCTTCCCCTCCATCGTG & 113 & & 60 \\
\hline & $\beta$-actinR1 & AGGGTGAGGATGCCTCTCTT & & & \\
\hline \multirow[t]{8}{*}{ MSP } & TET1m4 & GTCGGTAGGCGTIITTCGC & 173 & 40 & 60 \\
\hline & TET1m8 & CCCAACTCACCGCTAACCG & & & \\
\hline & TET1U4 & GAGTTGGTAGGTGTTITTTGT & 175 & 40 & 58 \\
\hline & TET1u8 & CCCAACTCACCACTAACCA & & & \\
\hline & DKK1m1 & ATITGTAGTCGAATCGGTAC & 127 & 40 & 60 \\
\hline & DKK1m2 & CCGAATAACTCCCGCTACG & & & \\
\hline & DKK1U1 & TGATITTGTAGTTGAATTGGTAT & 131 & 40 & 58 \\
\hline & DKK1U2 & ACCCAAATAACTCCCACTACA & & & \\
\hline
\end{tabular}


Table 1 List of primers used in this study (Continued)

\begin{tabular}{|c|c|c|c|c|c|}
\hline PCR & Primer & Sequence $\left(5^{\prime}-3^{\prime}\right)$ & Product size (bp) & PCR Cycles & Annealing temperature $\left({ }^{\circ} \mathrm{C}\right)$ \\
\hline & $D K K 2 m 1$ & AGAGTTAAATCGTCGAGATTTC & 146 & 40 & 60 \\
\hline & $D K K 2 m 2$ & CTAAAAACAATCAAATACGAAACG & & & \\
\hline & DKK2U1 & GGAGAGTTAAATTGTTGAGATTT & 149 & 40 & 58 \\
\hline & DKK2U2 & ACTAAAAACAATCAAATACAAAACA & & & \\
\hline & DKK3m3 & TTTCGGGTATCGGCGTTGTC & 148 & 40 & 60 \\
\hline & DKK3m4 & ACTAAACCGAATTACGCTACG & & & \\
\hline & DКKЗиз & GTTITITGGGTATTGGTGTTGTT & 135 & 40 & 58 \\
\hline & DKK3U4 & CAACTAAACCAAATTACACTACA & & & \\
\hline & DACT1m3 & CGGGATAGTAGTAGTCGGC & 118 & 40 & 60 \\
\hline & DACT1m4 & CGCTAAAACTACGACCGCG & & & \\
\hline & DACT1u3 & GTTGGGATAGTAGTAGTTGGT & 123 & 40 & 58 \\
\hline & DACT1u4 & AAACACTAAAACTACAACCACA & & & \\
\hline & DACT2m3 & CGTGTAGATTTCGTITTCGC & 200 & 40 & 60 \\
\hline & DACT2m4 & CCGAAAATCCGCCCGACG & & & \\
\hline & DACT2U3 & TGTGTGTAGATITGTIITTGT & 203 & 40 & 58 \\
\hline & DACT2U4 & CCCCAAAAATCCACCCAACA & & & \\
\hline & SFRP1m 1 & TGTAGTITTCGGAGTTAGTGTCGCGC & 126 & 40 & 60 \\
\hline & SFRP1m2 & CCTACGATCGAAAACGACGCGAACG & & & \\
\hline & SFRP1U1 & GTITGTAGTITTGGAGTTAGTGTTGTGT & 137 & 40 & 58 \\
\hline & SFRP1U2 & CTCAACCTACAATCAAAAACAACACAAACA & & & \\
\hline & $S F R P 2 m 1$ & GGAGTTITTCGGAGTTGCGC & 128 & 40 & 60 \\
\hline & SFRP $2 m 2$ & CTCTTCGCTAAATACGACTCG & & & \\
\hline & SFRP2U1 & GTTGGAGTITITGGAGTTGTGT & 133 & 40 & 58 \\
\hline & SFRP2U2 & СТСТСТТСАСТАAАТАСАAСTCA & & & \\
\hline \multirow[t]{2}{*}{ BGS } & TET1BGS1 & TTGTTITITATTGTGGATTITTG & 384 & 40 & 60 \\
\hline & TET1BGS2 & AACCCACCCCTAAAACAAC & & & \\
\hline \multirow[t]{6}{*}{ Chip-PCR } & DACT2F & CGTGCAGACCCCGCCCTC & 113 & & 60 \\
\hline & DACT2R & GATCCCGAGCTGTGTCGCG & & & \\
\hline & $S F R P 2 F$ & TGTCCCGCTTCTCCGCG & 98 & & 60 \\
\hline & SFRP2R & GAGTTCGAGCTTGTCCCG & & & \\
\hline & Wnt5AF & CTCTCCGTGGAACAGTTGC & 136 & & 60 \\
\hline & Wnt5AR & GCAGAGCTGGGATGCGC & & & \\
\hline
\end{tabular}

enhanced chemiluminescence (ECL; Amersham Pharmacia Biotech, Piscataway, NJ, USA) at last.

\section{Colony formation assay}

Cells were stably transfected with pcDNA3.1, pcDNA3.1-TET1-CD, or pcDNA3.1-TET1-CD-mut plasmids and plated at 400 or 800 cells/well in six-well plates for HNE1 and HONE1, respectively. Following selection for 10 days with G418, colonies ( $\geq 50$ cells/ colony) were stained with gentian violet (ICM Pharma, Singapore) and counted. All experiments were performed three times.

\section{Cell proliferation assay}

Stably transfected HNE1 and HONE1 cells were collected, counted, and plated in 96-well plates. Proliferation was assayed after 24, 48, and $72 \mathrm{~h}$ by the MTS Reagent (Promega, Madison, WI, USA) (absorbance $490 \mathrm{~nm}$ ). All experiments were performed three times.

\section{Wound healing and transwell assays}

Stably transfected TET1-CD and vector plasmid-transfected HNE1 and HONE1 cells were cultured in six-well plates until confluent. The monolayers were scratched, washed with PBS, and cultured in 0\% FBS-RPMI 1640. 
Cells were photographed at 0,12 , and $24 \mathrm{~h}$ at $\times 100$ magnification by light microscopy (Leica DMI4000B, Milton Keynes, Bucks, UK). All experiments were performed three times.

Cell migration and invasion were evaluated in $8-\mu \mathrm{m}$ pore size Transwell chambers (Corning Life Sciences, Corning, NY, USA). The Transwell membranes were pre-coated with Matrigel (BD Biosciences) for the invasion assay. Cells stably expressing empty-vector or TET1-CD were washed twice in PBS and serum-free medium and plated into Transwell chamber inserts in 24-well plates after counting. The lower chambers contained $700 \mu \mathrm{L}$ culture medium with $20 \%$ FBS. After incubation in FBS-free RPMI 1640 for $24 \mathrm{~h}$, the cells that had migrated into the lower chamber were fixed in $4 \%$ paraformaldehyde for $30 \mathrm{~min}$ and stained with $0.1 \%$ crystal violet for $30 \mathrm{~min}$. The nonmigrating cells in the upper chamber were removed, and the stained cells in three randomly selected fields were photographed by $\times 100$ magnification and counted. All experiments were performed three times.

\section{Flow cytometry analysis and apoptosis assay}

For cell cycle analysis, HNE1 and HONE1 cells were seeded in six-well plates and transfected with $4 \mu \mathrm{g}$ of TET1-CD or empty-vector control plasmids using lipofectamine 2000 (Invitrogen Corporation, Carlsbad, CA, USA) following the manufacturer's protocol. After $48 \mathrm{~h}$, cells were harvested, washed, fixed in ice-cold 70\% ethanol overnight at $4{ }^{\circ} \mathrm{C}$, and treated with $100 \mu \mathrm{L}$ of $50 \mathrm{mg} / \mathrm{L}$ propidium iodide (PI; BD Pharmingen, San Jose, CA, USA) for $30 \mathrm{~min}$ at $4{ }^{\circ} \mathrm{C}$ in the dark. Data were analyzed with CELL Quest software (BD Biosciences, San Jose, CA, USA). Annexin V-fluorescein isothiocyanate (FITC; BD Pharmingen) and PI double staining were used for apoptosis analysis. Briefly, the transfected cells were washed with PBS, stained with AnnexinV-FITC and PI for $5 \mathrm{~min}$, and visualized immediately by flow cytometry analysis. The percentage of apoptotic cells was then calculated. All experiments were performed three times.

\section{Western blot assay}

Transfected cells were washed with ice-cold PBS and lysed using protein extraction reagent (Thermo Scientific, Rockford, IL, USA) containing phenylmethylsulfonyl fluoride and a protease inhibitor cocktail (Sigma-Aldrich, St Louis, MO). The lysate was centrifuged at $4{ }^{\circ} \mathrm{C}$ for $10 \mathrm{~min}$ at $10,000 \mathrm{~g}$, the liquid supernatant was collected, and $40 \mu \mathrm{g}$ protein lysate aliquots were separated by sodium dodecyl sulfate-polyacrylamide gel electrophoresis (SDS-PAGE) and transferred to PVDF membranes (Bio-Rad, Hercules, CA, USA). The membranes were blocked with $5 \%$ low-fat milk for $1 \mathrm{~h}$ and subsequently incubated with primary antibodies (dilution 1:1000) overnight at $4{ }^{\circ} \mathrm{C}$ followed by incubation with an anti-mouse
IgG or anti-rabbit IgG secondary antibody. The primary antibodies were Myc-tag (\#2276; Cell Signaling Technology), active $\beta$-catenin (\#19807s; Cell Signaling Technology), total $\beta$-catenin (\#9562; Cell Signaling Technology), c-Myc (\#13987s; Cell Signaling Technology), and cyclin D1 (\#1677-1; Epitomics); $\beta$-actin (ARG62346; arigo) was used as a control. Proteins were visualized using an enhanced chemiluminescence (ECL) kit (Amersham Pharmacia Biotech, Piscataway, NJ, USA).

\section{Immunofluorescence staining}

Cells were incubated on coverslips in 24-well plates and transfected with TET1-CD. After $48 \mathrm{~h}$, cells were fixed in paraformaldehyde and processed for double-label immunofluorescence by incubating with HA-tag (\#3724; Cell Signaling Technology), Myc-tag (\#2276; Cell Signaling Technology), total $\beta$-catenin (\#2677; Cell Signaling Technology), or active $\beta$-catenin (\#19807s; Cell Signaling Technology) primary antibodies at $4{ }^{\circ} \mathrm{C}$ overnight and fluorochrome-labeled secondary antibodies against mouse or rabbit IgG in the dark condition. Cells were then stained with 4', 6-diamidino-2-phenylindole (DAPI) and subsequently visualized by a confocal laser scanning microscope and photographed.

\section{Dual-luciferase reporter assay}

Cells stably transfected with vector control and TET1-CD were plated into 24-well plates and transiently transfected with TOP/FOP-flash and Renilla luciferase reporter plasmids. The vector was the control and Renilla luciferase reporter phRL-TK was the internal control. After $48 \mathrm{~h}$, cells were lysed in lysis buffer for $15 \mathrm{~min}$ at room temperature with shaking. Lysates were centrifuged, the supernatant was extracted, and luciferase activity was detected using a dual-luciferase reporter assay kit (Promega).

\section{Immunohistochemistry assay}

Hematoxylin and eosin ( $\mathrm{H} \& \mathrm{E})$ staining is used to identify normal septum deviation and cancerous tissue morphology. Immunohistochemistry (IHC) was performed using an UltraSensitive SP Kit (Maixin-Bio, Fujian, China) following the manufacturer's instructions. Normal septum deviation and NPC tissues were formalin-fixed and paraffin-embedded. Sections were deparaffinized, and following antigen retrieval by heating in a microwave in $\mathrm{pH} 6.0$ sodium citrate solution, sections were incubated with TET1 (1:150; GTX124207; Gene Tex) and 5-hmC (1:150; \#39769; active motif) primary antibodies at $4{ }^{\circ} \mathrm{C}$ overnight. Following incubation with secondary antibodies, and DAB and hematoxylin staining, cells were evaluated using Image-Pro Plus, version 6.0 (IPP6.0, Silver Spring, MD, USA). 
The universal German semi-quantitative scoring system [35] was used to assess TET1 protein expression by the intensity of nuclei staining and number of stained cells. Briefly, each sample selected three to five random fields of vision at $\times 400$ magnification, through the score of staining intensity $(0=$ no; 1 = weak; 2 = moderate; 3 = intense $)$ was multiplied by the score of the range of stained cells $(0=0 \% ; 1=1 \sim 24 \% ; 2=25 \sim 49 \% ; 3=50 \sim 74 \%$; $4=75 \sim 100 \%)$ to give the score of one field of vision, and then taking the average (range from 0 to 12). The scores for immunostaining were scored by two individuals who did not know the sample information. Student's $t$ test was used for statistical analysis.

\section{Methylated DNA immunoprecipitation (MeDIP) and} Hydroxymethylated DNA immunoprecipitation (hMeDIP)

Two micrograms of sonicated DNA was denatured at $95{ }^{\circ} \mathrm{C}$ for $10 \mathrm{~min}$, immediately cooled on ice for $10 \mathrm{~min}$, and diluted in $500 \mu \mathrm{l}$ of IP buffer (10 mM Na-Phosphate pH $7.0140 \mathrm{mM} \mathrm{NaCl} 0.05 \%$ Triton X-100), $50 \mu$ las input. Then, add $10 \mu \mathrm{l}$ of anti-5mC (\#28692; Cell Signaling
Technology) or anti-5hmC (\#39769; active motif; Cell Signaling Technology), IgG (\#2729, Cell Signaling Technology) as control. After $2 \mathrm{~h}$ incubation at $4{ }^{\circ} \mathrm{C}$ with overhead shaking, $30 \mu \mathrm{l}$ of $50 \%$ protein A/G-Sepharose magnetic beads were added and incubated for another $2 \mathrm{~h}$. Put the tube on the magnetic beam for $5 \mathrm{~min}$ and discard supernatant. After five washes with IP buffer, DNA was eluted with Proteinase $\mathrm{K}$ for $2 \mathrm{~h}$, then purified using the QIAQuick PCR Purification Kit (Qiagen) according to the manufacturer's instructions. DNA was analyzed by quantitative real-time PCR by using a SYBR GreenER kit (Invitrogen). Primers sequences are provided in Table 1 . Fold enrichment was calculated as follows: \%Input $=10 \% \times 2^{\wedge}\left(\mathrm{CT}^{\text {input }}-\mathrm{CT}^{\text {sample }}\right)$.

\section{Statistical analysis}

Continuous variables were reported as the mean value \pm standard deviation (SD) compared by Student's $t$ test. Categorical values were compared by the chi-square test or Fisher's exact test. Differences accepted for significance was $p<0.05$. All data analyses were carried out
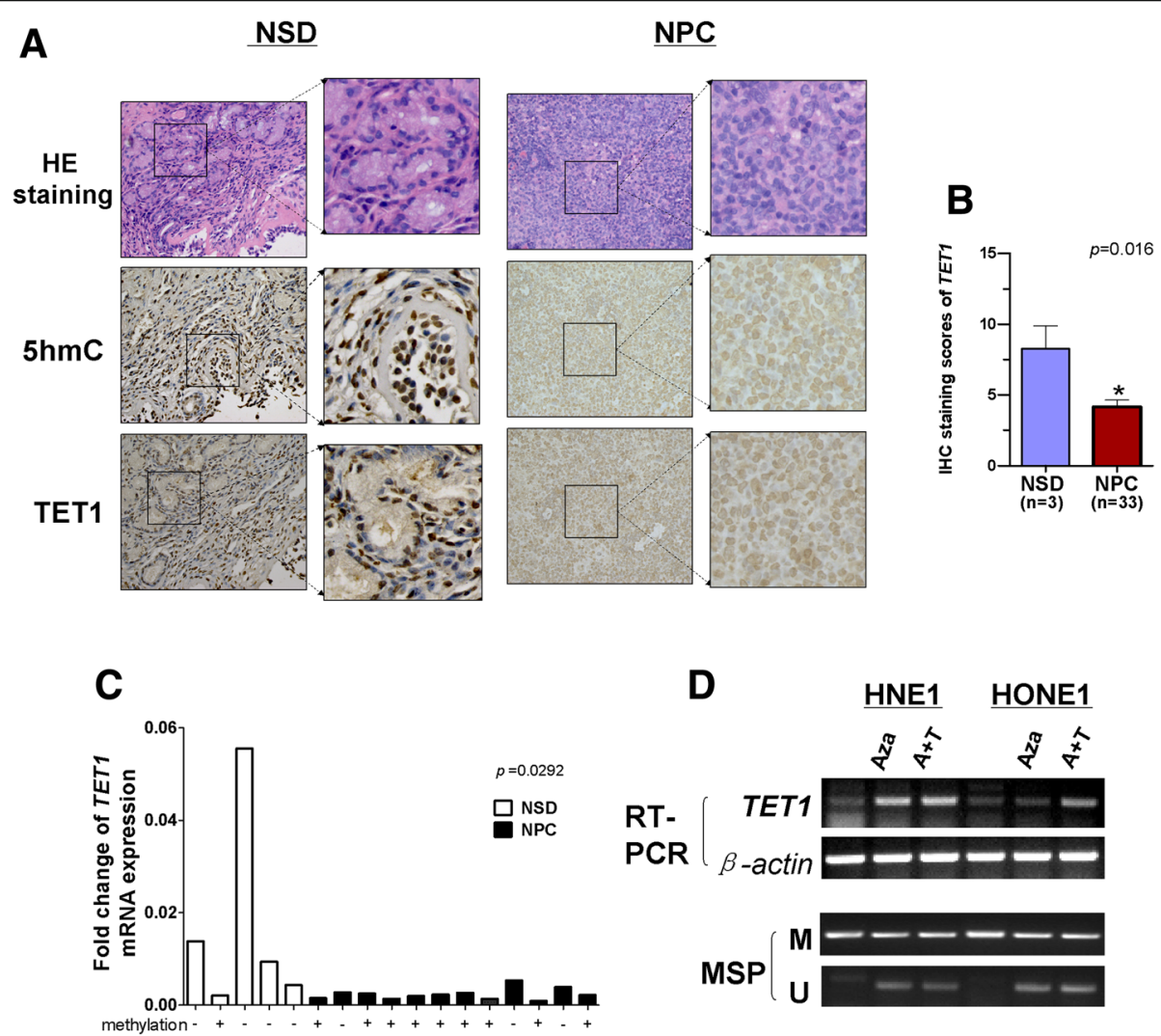

Fig. 1 Expression of TET1 protein and mRNA in normal septum deviation tissues (NSD) and NPC. a Representative IHC images of TET1 and 5-hmC expression in normal septum deviation tissue and NPC tissue. The staining scores of TET1 expression was shown in (b). c TET1 mRNA expression in normal septum deviation tissue and NPC assayed with qRT-PCR, $\beta$-actin was used as a control. Results are means \pm SD, $p=0.0292$ (NPC), $p=0.0088$ (HNSC). $\mathbf{d}$ Pharmacological demethylation of TET1 CGI by AZA (A) with or without TSA (T) induced its expression. TET1 expression before and after drug treatment was determined with RT-PCR, and demethylation was confirmed with methylation-specific PCR 
with the statistical analysis software package SPSS22.0 (SPSS Inc., Chicago, IL, USA). All biostatistics calculations were performed using Prism (Graphpad Software, Inc., La Jolla, California).

\section{Results}

TET1 expression is downregulated in NPC cell lines

Our previous studies found that TET1, 2, and 3 are expressed in human adult and fetal tissues and that only TET1 was downregulated in NPC cell lines [29]. H\&E staining showed normal epithelial and cancer cell morphology and IHC staining showed that both TET1 and $5 \mathrm{hmC}$ expression were higher in 3 normal septum deviation than in 33 NPC tissues (Fig. 1a, b). Unfortunately, there was no correlation between TET1 expression and clinical and pathological features (Table 2). qRT-PCR was used to assay TET1 mRNA expression and revealed that it was higher in normal nasal tissues than NPC $(p=0.0292)$, and most samples with low TET1 expression show considerably high methylation in CpG island of TET1 promoter (Fig. 1c). When methylated or silenced HNE1 and HONE1 nasopharyngeal cells were treated with the demethylation reagent 5-aza-2'-deoxycytidine (Aza) with or without trichostatin A (TSA) histone deacetylase, PCR confirmed that TET1 expression was restored with a significant decrease of TET1 promoter methylation (Fig. 1d). The results indicate that CpG methylation of TET1 promoter mediated its silencing in NPC cells.
TET1 promoter is frequently methylated in NPC tissues The CpG islands of TET1 and primer design for MSP have been shown in previous study [29]. Methylation-specific PCR was used to assay 55 NPCs and 9 surgical margin tissue samples. Hyper-methylation of the TET1 promoter was observed in 45/55 (81.8\%) NPCs and 4/9 (44.4\%) in surgical margin tissues, indicating that methylation of the TET1 promoter was a common event in NPC (Fig. 2a). BGS analysis further confirmed the MSP data (Fig. 2b).

\section{Ectopic expression of TET1 suppresses NPC cell growth mediated by its catalytic domain}

As TET1 was downregulated in NPC and expressed in normal septum deviation, the tumor repressive of TET1 overexpression on the growth of NPC cells was evaluated. RT-PCR and Western blotting confirmed the expression of TET1 mRNA and protein in stably transfected HNE1 and HONE1 cells, which had few intrinsic TET1 expressions (Fig. 3a, b). MTS and colony formation assays revealed that TET1 significantly suppressed cell viability at 24,48 , and $72 \mathrm{~h}\left({ }^{*} p<0.05,{ }^{* * *} p<\right.$ 0.01 , and ${ }^{* * * *} p<0.001$, respectively) and decreased colony formation by $45-55 \%$ compared with cells transfected with empty vectors, but no difference between empty vector group and TET1-CD-mut group, i.e., with inactive catalytic domains (Fig. 3c, d). The results indicated that re-expression of TET1 with an active catalytic domain suppressed the growth of NPC cell lines.

Table 2 Association between TET1 expression and clinical characteristics in NPC tissues

\begin{tabular}{|c|c|c|c|c|c|c|}
\hline \multirow[t]{2}{*}{ Characteristics } & \multirow{2}{*}{$\begin{array}{l}\text { Number } \\
(n=33)\end{array}$} & \multicolumn{4}{|c|}{ TET1 expression } & \multirow{2}{*}{$\begin{array}{l}p \\
\text { value }\end{array}$} \\
\hline & & None & Low & Moderate & High & \\
\hline \multicolumn{7}{|l|}{ Age (years) } \\
\hline$\geqq 48$ & 16 & 2 & 9 & 4 & 1 & \multirow[t]{2}{*}{0.778} \\
\hline$<48$ & 17 & 1 & 8 & 6 & 2 & \\
\hline \multicolumn{7}{|l|}{ Gender } \\
\hline Female & 9 & 0 & 4 & 4 & 1 & \multirow[t]{2}{*}{0.548} \\
\hline Male & 24 & 3 & 13 & 6 & 2 & \\
\hline \multicolumn{7}{|l|}{ WHO histological type } \\
\hline I (keratinizing) & 5 & 0 & 2 & 3 & 0 & \multirow[t]{2}{*}{0.401} \\
\hline I//II (non-keratinizing) & 28 & 3 & 15 & 7 & 3 & \\
\hline \multicolumn{7}{|l|}{ Clinical stages } \\
\hline । & 6 & 1 & 4 & 1 & 0 & \multirow[t]{4}{*}{0.255} \\
\hline$\|$ & 13 & 1 & 8 & 4 & 0 & \\
\hline III & 12 & 1 & 5 & 3 & 3 & \\
\hline IV & 2 & 0 & 0 & 2 & 0 & \\
\hline \multicolumn{7}{|l|}{ Lymph node metastasis } \\
\hline positive & 21 & 1 & 9 & 8 & 3 & \multirow[t]{2}{*}{0.179} \\
\hline negative & 12 & 2 & 8 & 2 & 0 & \\
\hline
\end{tabular}



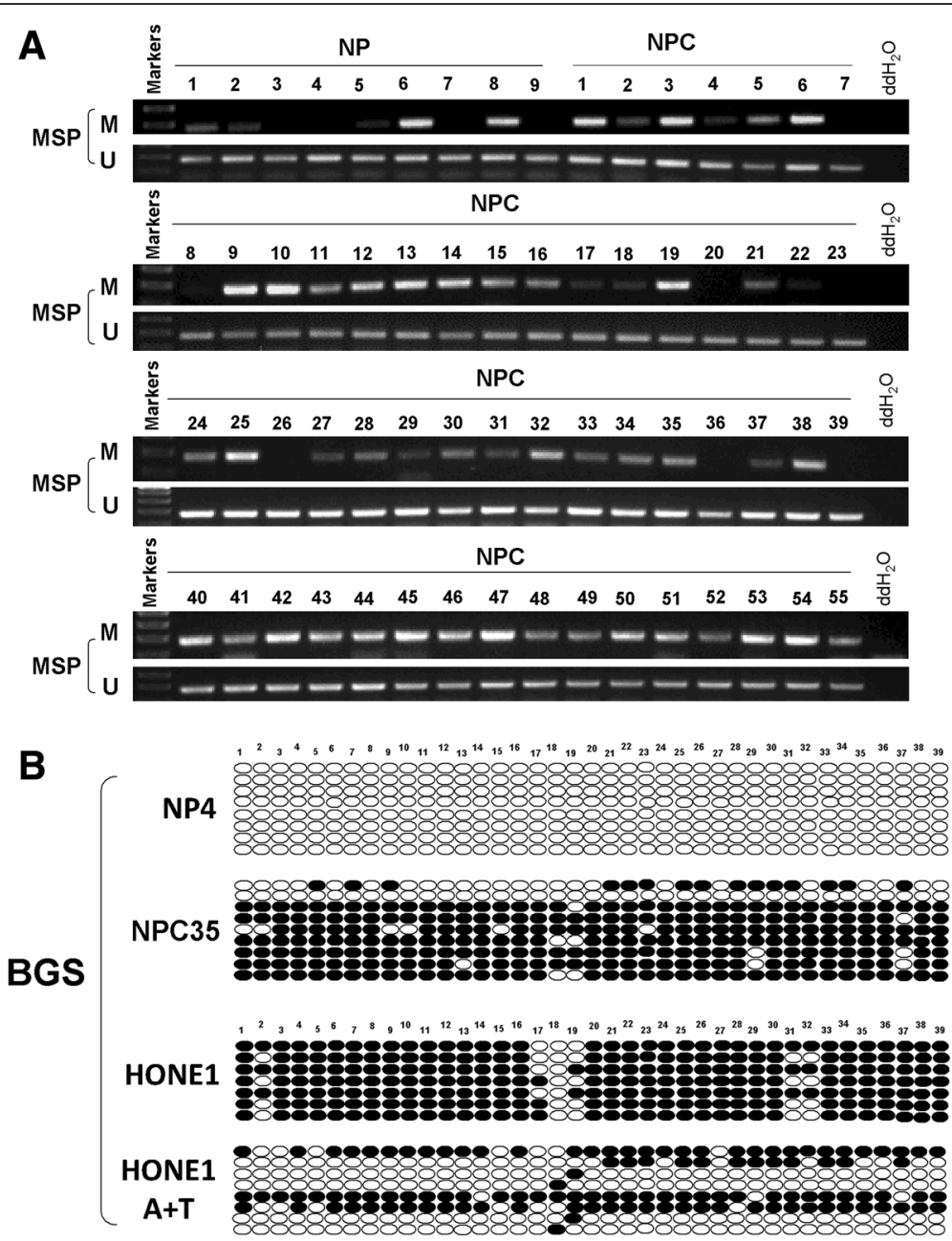

Fig. 2 The methylation status of TET1 in NSD, surgical margin tissues, nasopharyngeal carcinoma (NPC) tissues, and nasopharyngeal carcinoma cells lines. a Promoter methylation of TET1 in surgical margin tissues and nasopharyngeal carcinoma tissues as measured by MSP. M: methylated; U: unmethylated. b Bisulfite genomic sequencing confirmed the methylation status of TET1 CpG sites in NSD, NPC tissues, and HONE1 cells with or without A+T treatment

TET1 induces NPC cell cycle arrest in G0-G1 phase and apoptosis

Flow cytometry was used to determine whether TET1 affected the cell cycle and apoptosis of NPC cells. TET1-transfection resulted in a 20 and $9 \%$ increase of the numbers of HNE1 and HONE1 cells in the G0/ G1 phase $(p<0.001)$ compared with controls, respectively (Fig. 4a). Transfection also increased the number of apoptotic cells (Fig. 4b). These results demonstrated that TET1 inhibited the proliferation of NPC cells by inducing cell cycle arrest and promoted apoptosis.

TET1 suppresses NPC cells migration and invasion via regulating epithelial-mesenchymal transition Transwell chamber motility showed that motility was significantly suppressed in HNE1 and HONE1 cells expressing TET1 (Fig. 5a, b). Similar results were observed in wound healing assays (all $p<0.001$ ) (Fig. 5c, d). Matrigel invasiveness assays demonstrated that ectopic TET1 expression significantly inhibited HNE1 and HONE1 cell invasion in culture medium containing 20\% FBS (Fig. 6a, b). These results indicated that TET1-expression inhibited migration and invasion of NPC cells. The epithelial to mesenchymal transition (EMT) plays an important role in cancer progression and metastasis. To verify whether TET1 suppresses cell migration caused by inhibiting EMT, the expression of epithelial and mesenchymal markers was investigated. qRT-PCR showed the increase of E-cadherin and occludin and the decrease of N-cadherin, vimentin, and snail1 in TET1-expressed HNE1 and HONE1 cells (Fig. 6c). And immunofluorescence staining proved the same results in HONE1 cells (Fig. 6d). These results suggested that TET1 inhibits EMT in NPC cells. 

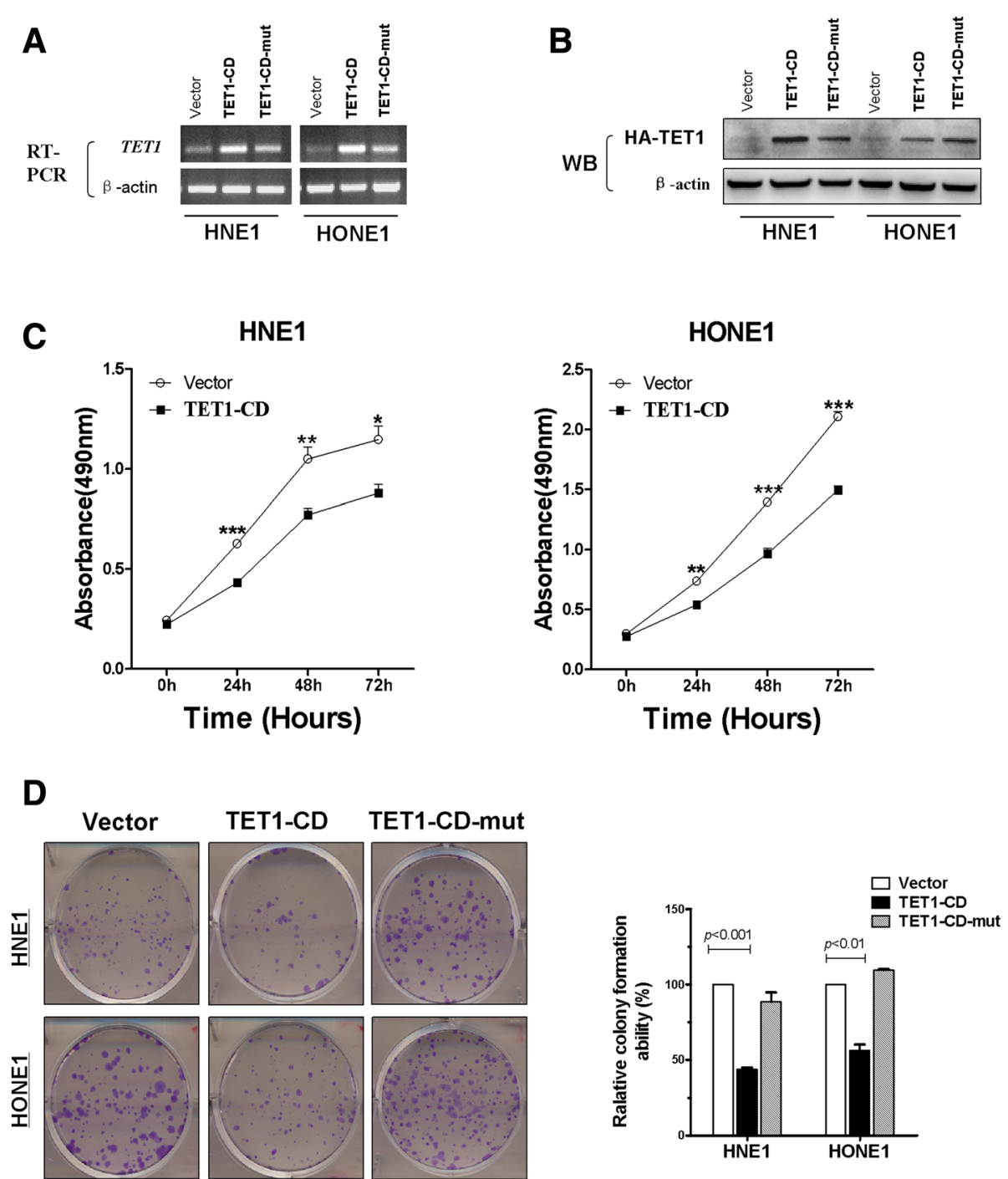

Fig. 3 TET1 suppresses NPC cells proliferation via its catalytic domain. a, b RT-PCR and Western blots show TET1 expression in vector controls, TET1-CD- and TET1-CD-mut-transfected HNE1 and HONE1 cells. c The proliferation assay of vector controls and TET1-expressing HNE1 and HONE1 cells. ${ }^{*} p<0.05,{ }^{* *} p<0.01,{ }^{* *} p<0.001$ (d). Colony formation assay of HNE1 and HONE1 cell transfected with Vector, TET1-CD and TET1-CD-mut

\section{TET1 inhibits the Wnt/ß-catenin signaling pathway}

Aberrant activation of the Wnt/ $\beta$-catenin signaling pathway was involved in NPC carcinogenesis. The evidence indicated that methylation of genes promoting negative Wnt regulators contributes to aberrant silencing and activation of Wnt/ $\mathrm{W}$-catenin signaling in human cancers. Western blotting, TOP/FOP-Flash, and immunofluorescence were used to investigate the effect of TET1 on Wnt/ $\beta$-catenin signaling in NPC cells. The expression of $\beta$-catenin and some downstream target genes of Wnt/ $\beta$-catenin were confirmed in NPC cells. Active $\beta$-catenin, c-Myc, and cyclinD1 were downregulated, with no significant change in total $\beta$-catenin in NPC cells overexpressed TET1 (Fig. 7a). TOP-flash assays found that TET1 overexpression had a significant inhibitory effect on $\beta$-catenin/TCF activity compared with FOP-flash controls (Fig. 7b). Immunofluorescence confirmed that nuclear expression of active $\beta$-catenin was decreased by TET1 overexpression, and total $\beta$-catenin has no significant change (Fig. 7c, d). Collectively, the data demonstrated that TET1 inhibited the $\mathrm{Wnt} / \beta$-catenin signaling pathway in NPC cells.

TET1 renews expression of Wnt antagonists by demethylation of their promoter

To determine how TET1 influenced Wnt/ $\beta$-catenin signaling, the expression of Wnt pathway antagonists, including DACT (DACT1,2,3), SFRP (SFRP1,2,3), DKK 

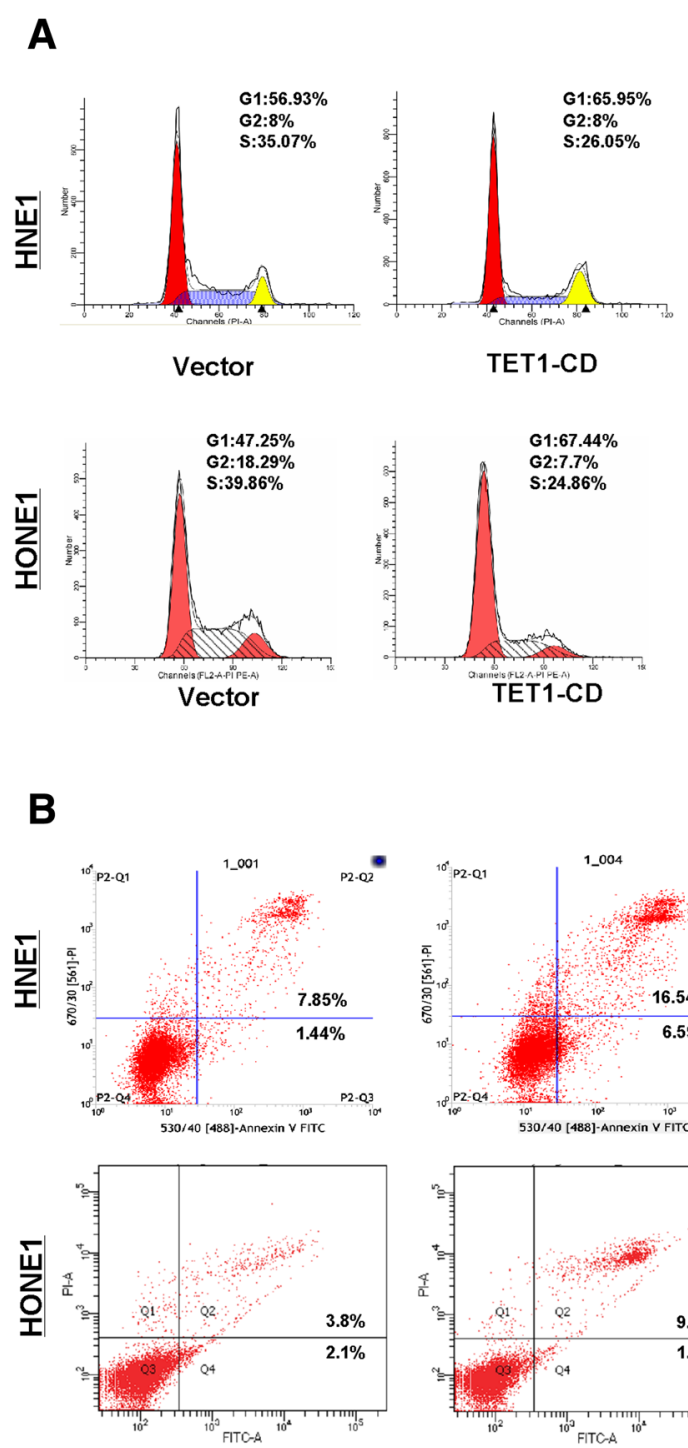

Vector
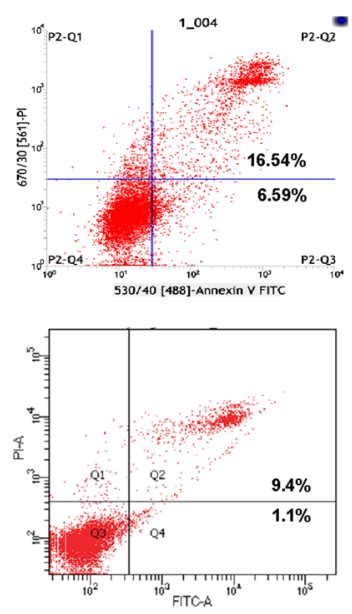

TET1-CD
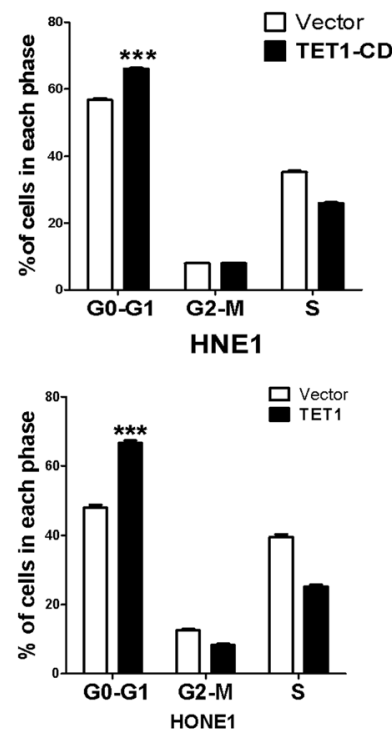

Fig. 4 TET1 induces cell cycle arrest at GO/G1 phase and induces cell apoptosis. a Left: Representative cell cycle distribution vector- and TET1tranfected HNE1 and HONE1 cells by flow cytometry analysis. Right: Data summary $\left(^{* * *} p<0.001\right)$. b Apoptotic cells are double-stained with Annexin V-FITC and PI. Cells were indicated as in a

(DKK1-3) family genes, and WNT proteins (include WNT1,3,3A,4, WAN5A, WNT5B, WNT7A, WNT7B) in HNSN (head and neck squamous cell normal tissues) and HNSC (head and neck squamous cell carcinoma) was analyzed. DACT $(1,2,3)$, WNT5A, and WNT7B were significantly positive correlation with $\operatorname{TET} 1(p<$ 0.05), and WNT4 and WNT7A were negative correlation with TET1 in the TCGA Head and Neck Squamous cell Carcinoma database $(p<0.05$, Additional file 1: Figure S1). We further found that $D A C T 2$ and WNT5B had the low-expression and hypermethylation in HNSC compared with HNSN (Additional file 2: Figure S2), data from TCGA (http:// methhc.mbc.nctu.edu.tw/php/index.php). Based on above information, DACT $(1,2,3)$, WNT5A, WNT5B, and WNT7B were most likely to be affected by TET1 in NPC.

Dot-blot assays were used to characterize $5 \mathrm{hmC}$ and $5 \mathrm{mC}$ expression in NPC cell lines that over-expressed TET1. TET1 re-expression in transfected TET1-silenced cells resulted in increased levels of $5 \mathrm{hmC}$ and decreased levels of $5 \mathrm{mC}$ compared with empty-vector transfected cells (Fig. 8a). To determine how TET1 influenced Wnt/ 

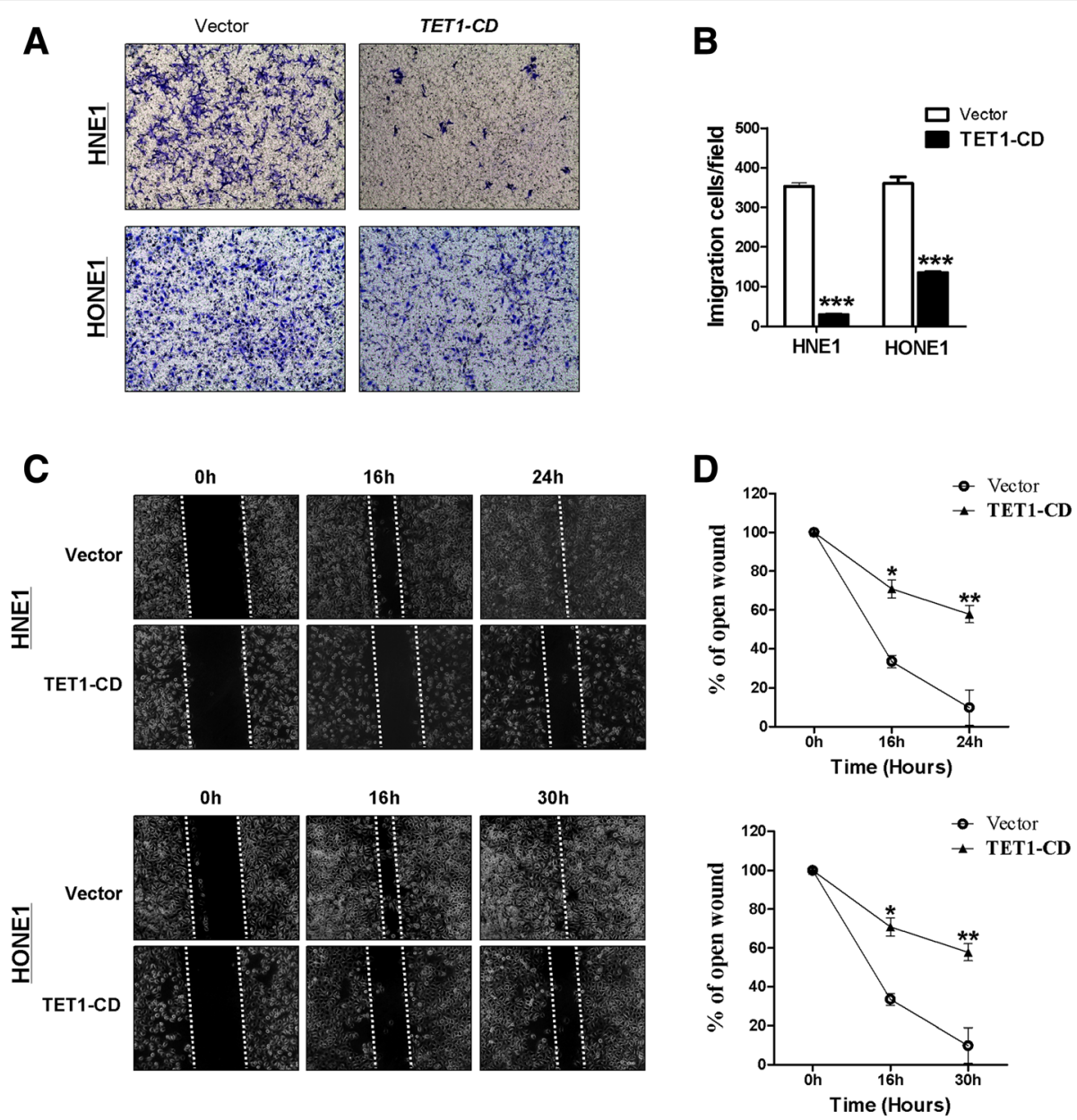

Fig. 5 TET1 suppresses HNE1 and HONE1 cells migration. a Transwell assay shows the migration of cells transfected with vector or TET1. Photographs show cells that crossed the membrane; the numbers of cells are shown in $\mathbf{b}\left({ }^{* * *} p<0.001\right)$. $\mathbf{c}$ Wound healing assay evaluated cell migration at $0,16,24$, and $30 \mathrm{~h}$. The wound healing rate was calculated in $\mathbf{d}$

$\beta$-catenin signaling, the expression of Wnt pathway antagonists, including DACT family genes (DACT1, 2, 3), DKK $(D K K 1,2,3)$ family genes, and SFRP family genes (SFRP1 and SFRP2), in TET1-transfected and vector-transfected cells was assayed by qRT-PCR and revealed an increase of DACT2, SFRP1, and SFRP2 mRNA expression in TET1-transfected cells compared with vector controls (Fig. 8b). In addition to Wnt pathway antagonists, we also found that the $W n t 5 A$ and $W n t 5 B$ were upregulated in TET1-transfected NPC cells (Fig. 8b). Furthermore, we found that Wnt5B, SFRP1, and SFRP2 were hypermethylated in nasopharyngeal carcinoma tissues (Additional file 3: Figure S3), and the hypermethylation of DKKs and DACTs in nasopharyngeal carcinoma tissues was also confirmed $[15,36]$. In the meantime, the reduced methylation status of DACT2, Wnt5A, and SFRP2 promoter was detected in TET1-CD-expressing tumor cells, with increased unmethylated sites at the promoter $\mathrm{CpG}$ regions (Fig. 8c), suggesting that TET1 really acts as a demethylase to renew expression of multiple TSGs in tumor cells. MeDIP and hMeDIP experiments were used to further confirm the demethylation of TET1; the results showed that TET1 can cause an increase of $5-\mathrm{hmC}$ and reduction of $5 \mathrm{mC}$ in promoters of Wnt5A, SFRP2, and DACT2 in HNE1 cells (Fig. 8d). These studies suggested that TET1 can cause demethylation of Wnt5A, SFRP2, and DACT2 in nasopharyngeal carcinoma cells and restore their expression.

\section{Discussion and conclusion}

TET1 has been described as a TSG, inhibiting proliferation in renal, colorectal, and gastric cancer [24, 25, 28], and migration and invasion in the lung, breast, and prostate cancer $[26,37,38]$. This study found that TET1 was expressed in normal septum deviation and downregulated in NPC tissues as well as NPC cells, and it was methylated in most NPC tissues and cells. This implies that TET1 was silenced by hyper-methylation in NPC. 

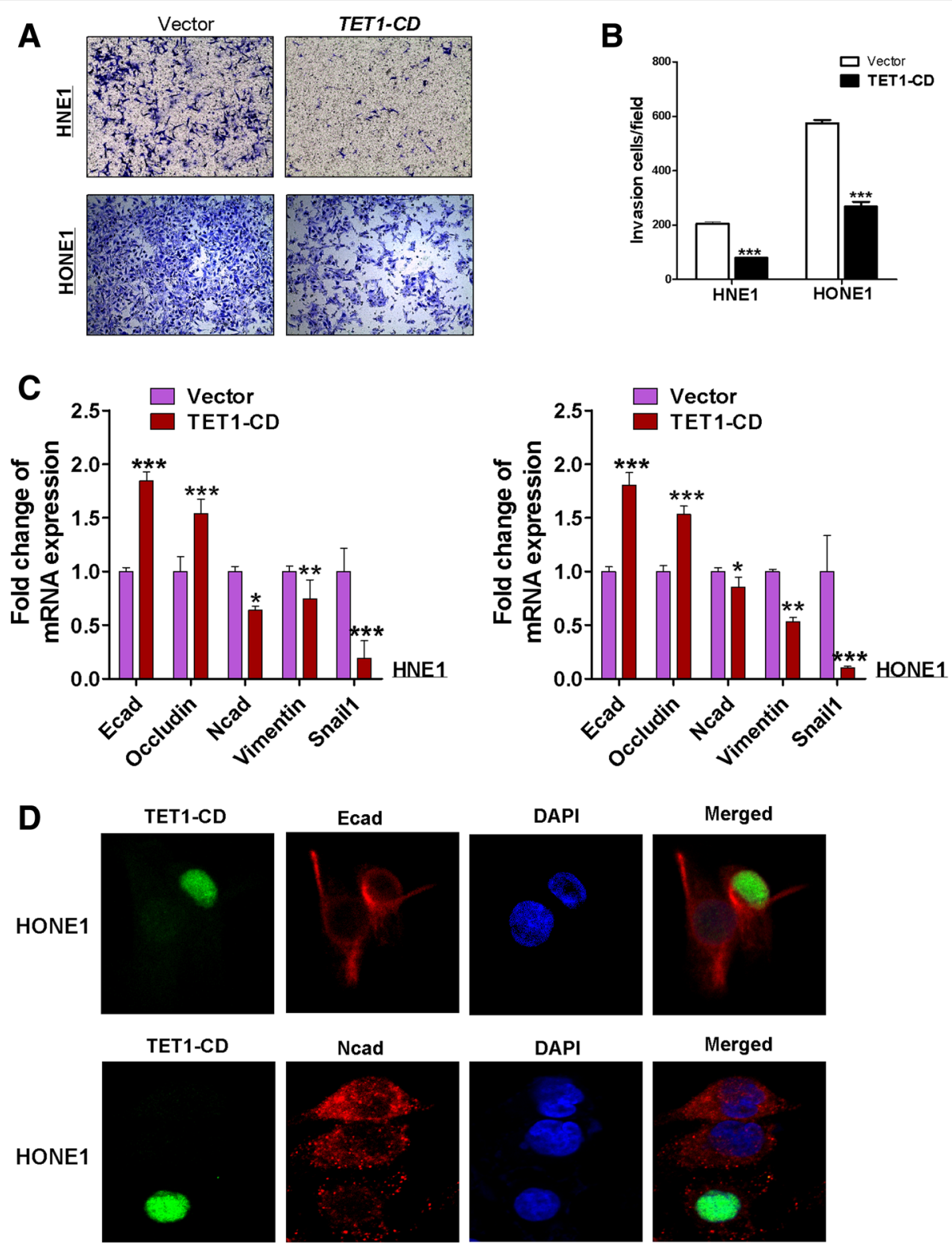

Fig. 6 TET1 suppressed NPC cells invasion by inhibiting EMT process. a Transwell assay of cell invasiveness showing cells that traversed the Matrigel-coated membrane. The analysis is shown in (b). c The expression of E-cadherin, N-cadherin, Occuldin, Vimentin, and snail1 in TET1-CDexpressing HNE1 and HONE1 cells was determined by qRT-PCR. $\mathbf{d}$ Subcellular location and expression of E-cadherin and N-cadherin in HONE1 cells by immunofluorescence staining

Demethylation by Aza with TSA can restore TET1 expression, but HONE1 treated only by Aza did not restore TET1 expression, indicating other mechanism involving TET1 expression. In present study, TET1 suppressed NPC cell proliferation, motility, and invasiveness. It also induced G0/G1 phase arrest and apoptosis. The results were consisted with other cancers. So, our data indicate that TET1 acts as a TSG activity in NPC.

Many TSGs act by inhibiting Wnt/ $\beta$-catenin signaling, a pathway known to be sensitive to TSG methylation in NPC [15, 16, 39-41], and TET1 was previously shown regulating the Wnt/ $\beta$-catenin pathway in colorectal cancer [24]. We found that TET1 inhibits the expression of $\beta$-catenin and its target genes, cyclinD1 and c-Myc. TET1 also prevented $\beta$-catenin interaction with T-cell factor/lymphoid enhancer factor (TCF/LEF) transcription factors, which are end point mediators of Wnt signaling. These data demonstrated that TET1 suppressed NPC cell growth by regulating the Wnt/ $\beta$-catenin signaling pathway.

To determine how TET1 regulated the $\mathrm{Wnt} / \beta$-catenin signaling pathway, the expression of downstream target 
A

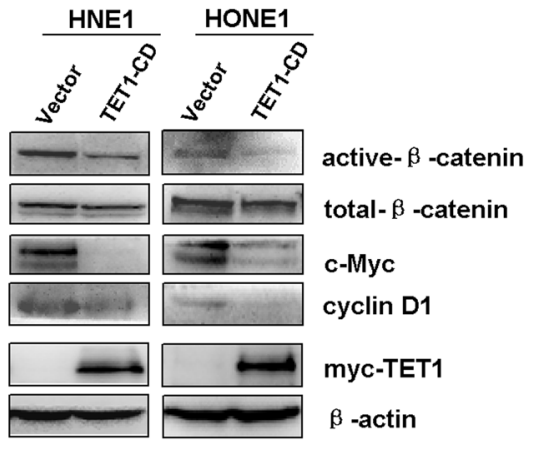

B

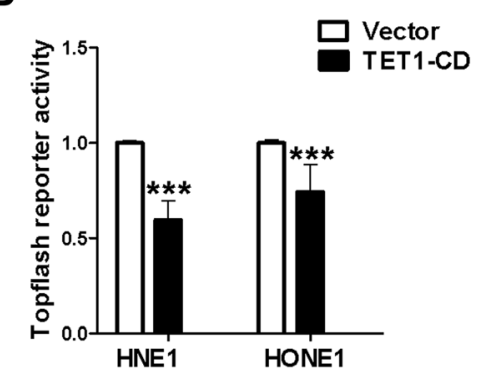

C

TET1-CD

Total- $\beta$-catenin

DAPI

Merged
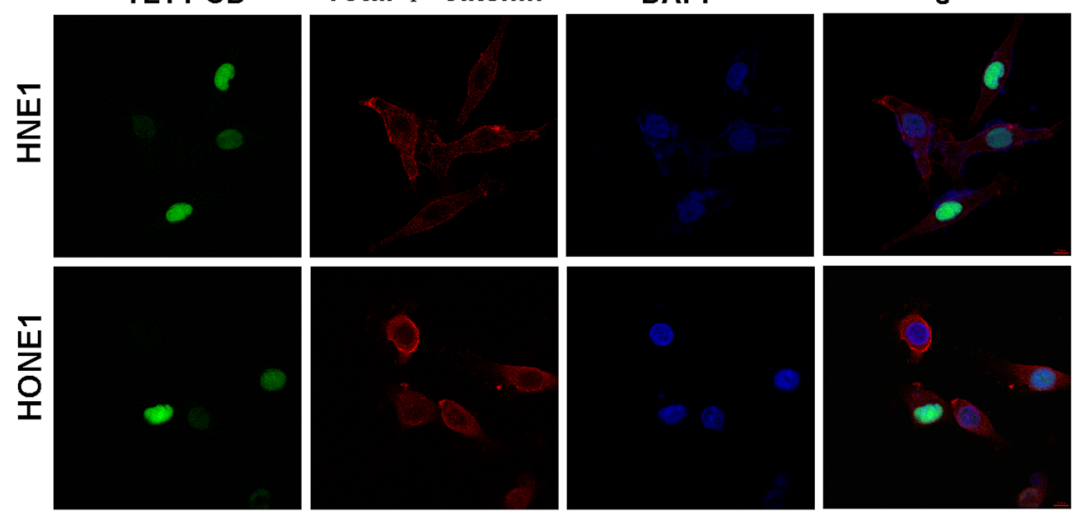

D TET1-CD

Active- $\beta$-catenin

DAPI

Merged
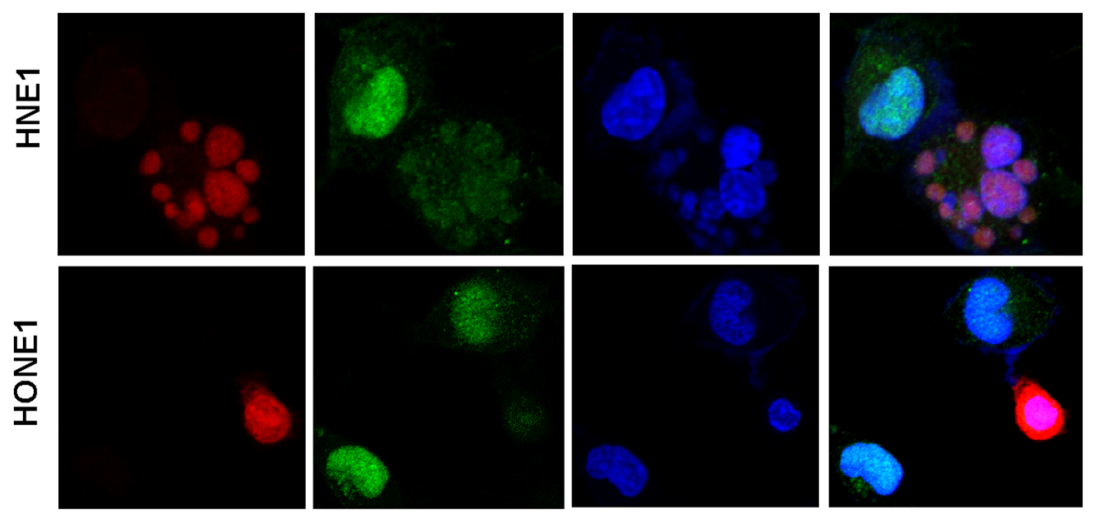

Fig. 7 TET1 inhibits Wnt/ $\beta$-catenin signaling pathway in NPC. a Western blots of $\beta$-catenin and the downstream Wnt/ $\beta$-catenin gene. b Top/Fop dual-luciferase reporter assay in HNE1 and HONE1 cells. Fop-flash was the control. c, d Subcellular location and expression of total $\beta$-catenin and active $\beta$-catenin by immunofluorescence staining

genes was assayed. It was previously demonstrated that TET1 could demethylate the PTEN gene, which codes for phosphatase and tensin homolog protein, to inhibit tumor growth in gastric cancer [42]. TET1 suppression of matrix metalloproteins in breast cancer inhibits tumor cell invasion through maintaining expression of TIMP2 and TIMP3 [37]. Epigenetic disruption of $\mathrm{Wnt} / \beta$-catenin signaling is crucial to several tumorigeneses, especially by promoter methylation of WNT antagonists [43-45].
Methylation of SFRPs, DACT2, DKK2, and DKK3 was frequently detected in NPC [15]. Recent works suggest that TET1 upregulates DKKs, which are Wnt pathway inhibitors that suppress CRC and ovarian cancer cell proliferation [24, 46]. Given the crucial role of TET1 in epigenetic modification of WNT antagonists, we thus aimed to thoroughly analyze the expression of Wnt pathway negative regulators in TET1-transfected cells. Our data clearly demonstrated that enforced expression 
A

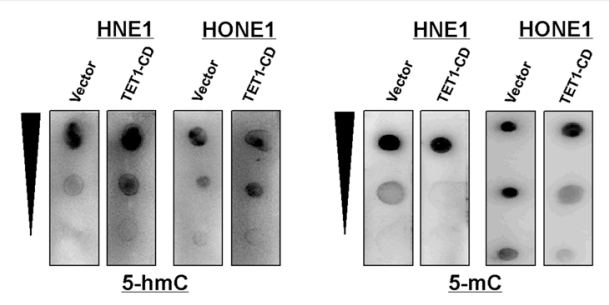

B
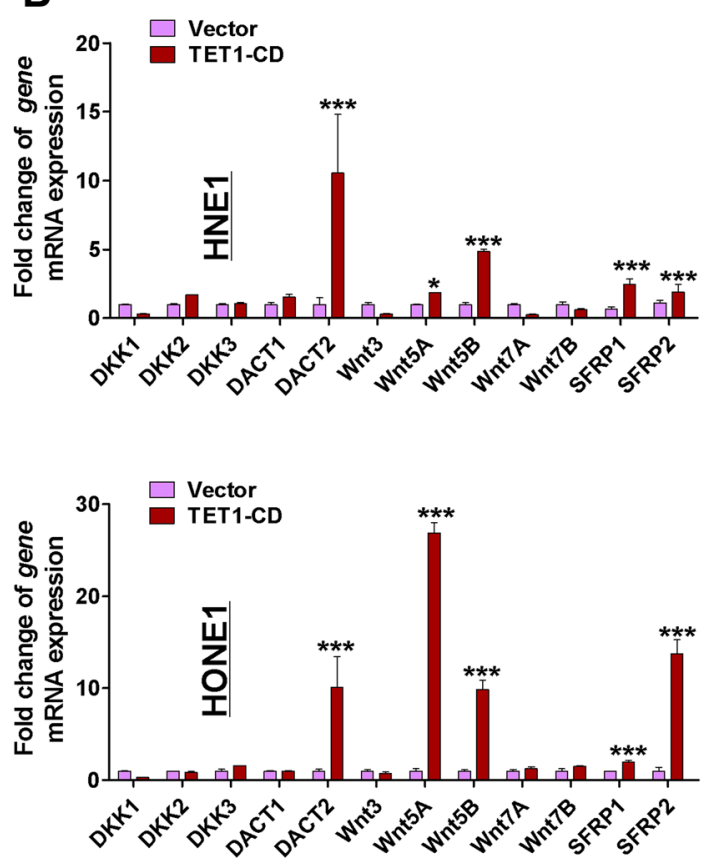

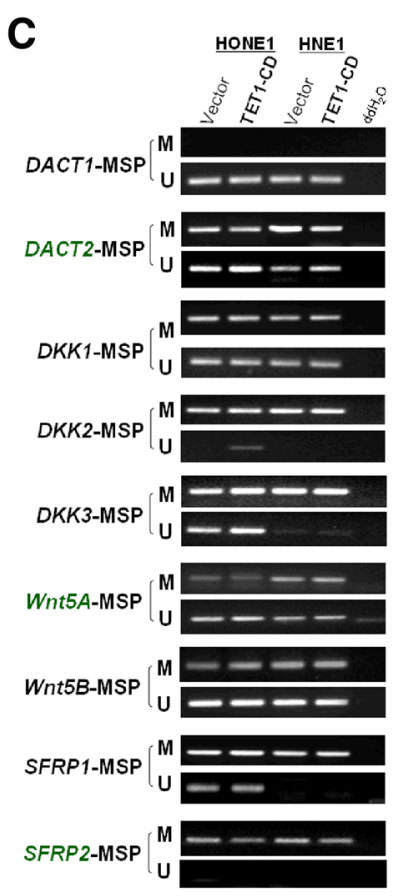

D

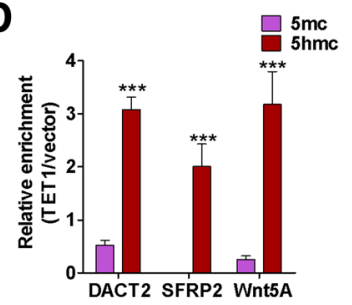

Fig. 8 TET1 restored the expression of Wht antagonists by demethylation of their promoter. a Dot-blot assay of 5-hmC and 5-mC in HNE1 and HONE1 cells with DNA concentration gradients. $\mathbf{b}$ The expression of target genes (DKKs, DACTs, SFRPs, and WNTs) in vector- and TET1-CD-transfected NPC cells was detected by qRT-PCR. c Methylation of DACTS, DKKS, SFRPS, and WNTs by MSP in vector- and TET1-transfected HNE1 and HONE1 cells. $\mathbf{d}$ The enrichment of 5-hmC and 5-mC in the promoter of Wnt5A, DACT2, and SFRP2 was detected by MeDIP-qPCR and hMeDIP-qPCR in HNE1 cells

of TET1 indeed significantly restore the expression of $D A C T 2$, SFRP1, and SFRP2, but no obvious influence to $D K K$ s family, DACT1 and DACT3. In addition, TET1 also increased the expression of Wnt5A and Wnt5B. And we have shown that $W n t 5 B, S F R P 1, S F R P 2$, and $D A C T 2$ are hypermethylated in nasopharyngeal carcinoma tissues [36]. But further analysis showed that the methylation status and 5-mC levels of DACT2, SFRP2, and $W n t 5 A$ promoter were decreased, accompanying with 5-hmC increased after TET1 upregulation, whereas there were no obvious changes in the promoters of $W n t 5 B$ and SFRP1, suggesting that other mechanisms are involved in $W n t 5 B$ and SFRP1 upregulation in TET1 transfected cell line. Li et al. have confirmed that SFRP2 function as TSG in NPC [15]. We also demonstrated that DACT2 act as a TSG in NPC [36].

The Wnt pathway includes canonical Wnt/ $\mathrm{B}$-catenin and non-canonical Wnt signaling, which have different roles in cancer progression [15]. The Wnts family includes 19 members. Wnt1, Wnt3, Wnt3A, Wnt7A, Wnt7B, and Wnt8 participate in $\beta$-catenin-dependent signaling; Wnt4, Wnt5A, and Wnt11 participate in $\beta$-catenin-independent signaling. The canonical Wnt protein Wnt3A promotes the secretion of $\beta$-catenin and cancer development. The noncanonical Wnt protein, Wnt5A, inhibits Wnt3A promotion of $\beta$-catenin secretion. So far, there are conflicting reports as to whether WNT5A acts as a tumor promotion genes or a tumor suppressor in cancers. Most of the evidence shows that WNT5A overexpression promotes the proliferation, invasion, and metastasis of cells in different types of cancers by promoting the epithelial-mesenchymal transition (EMT) and stem cell-like phenotypes [47-50]. However, contradictory reports showed that increased Wnt5A expression inhibited cell proliferation and motility, and negative Wnt5A expression contributes to the tumor 
lymph node metastasis and poor prognosis [51-54]. Recently, it was shown that the contradictory roles of Wnt5A are due to existence of various Wnt5A isoforms [55]. Further studies will be needed to identify functions of Wnt5A in NPC.

Added up, we provided the first evidence indicating that TET1 was a TSG in NPC cells and suppressed NPC proliferation, migration, and invasiveness progression via restoring Wnt pathway antagonist expression to antagonize activity of Wnt pathway. Furthermore, this study provides important insights into the regulation of TET1 for Wnt pathway.

\section{Additional files}

Additional file 1: Figure S1. The correlation between TET1 and DKKS, DACTs, SFRPs, and WNTs expression respectively in HNSC. Data from TCGA (http://methhc.mbc.nctu.edu.tw/php/index.php). (TIF 74 kb)

Additional file 2: Figure S2. The methylation and expression of TET1, DACTs, WNTs in HNSC. Data from TCGA (http://methhc.mbc.nctu.edu.tw/ php/index.php). (TIF $82 \mathrm{~kb}$ )

Additional file 3: Figure S3. Detection of WnT5B, SFRP1, and SFRP2 methylation in nasopharyngeal carcinoma tissues by MSP. HNE1 cells and $\mathrm{ddH}_{2} \mathrm{O}$ were used as positive and negative control, respectively. M: methylated; U: unmethylated. (TIF $201 \mathrm{~kb}$ )

\section{Abbreviations}

5-hmC: 5-Hydroxymethyl cytosine; 5-mC: 5-Methyl cytosine; AnnexinVFITC: Annexin V-fluorescein isothiocyanate; Aza: 5-Aza-2-deoxycytidine; BGS: Bisulfite genomic sequencing; DAPI: 4, 6-Diamidino- 2- phenylindole; EMT: Epithelial-to-mesenchymal transition; MSP: Methylation-specific PCR; NPC: Nasopharyngeal carcinoma; NSD: Normal nasal tissues; PVDF: Polyvinylidene difluoride; QRT-PCR: Quantitative real-time PCR; RTPCR: Semi-quantitative RT-PCR; SDS-PAGE: Sodium dodecyl sulfate polyacrylamide gel electrophoresis; TCF/LEF: T Cell factor/lymphoid enhancer factor; TET: Ten-eleven translocation; TET1: Ten-eleven translocation methyl cytosine dioxygenase1; TSA: Trichostatin A

\section{Acknowledgements}

The authors thank Prof. Qian Tao (the Chinese University of Hong Kong, Hong Kong, China) for generously providing cell lines, primers, and plasmids. This study was supported by National Natural Science Foundation of China (\#81572769,81372238) and Natural Science Foundation of Chongqing (2016ZDXM006)

\section{Availability of data and materials}

The data analysis used in this study was obtained from the TCGA database (http://methhc.mbc.nctu.edu.tw/php/index.php).

\section{Authors' contributions \\ JF and TX contributed to the conception and design of the research. JF and $Y Z$ performed the majority of the experiments in this study. JM, XH, BS, DZ, WP, and JT performed the experiments and analyzed the data. YJ collected the samples. JF wrote the manuscript. GR reviewed the article. TX reviewed data and the final version of the article. All authors reviewed and approved the final manuscript.}

\section{Ethics approval and consent to participate}

This research was approved by the Institutional Ethics Committees of the First Affiliated Hospital of Chongqing Medical University (\#20130306) and conformed to the tenets of the Declaration of Helsinki.

\section{Consent for publication}

Not applicable.

\section{Competing interests}

The authors declare that they have no competing interests.

\section{Publisher's Note}

Springer Nature remains neutral with regard to jurisdictional claims in published maps and institutional affiliations.

Received: 1 March 2018 Accepted: 24 July 2018

Published online: 03 August 2018

\section{References}

1. Chan AT, Gregoire V, Lefebvre JL, Licitra L, Hui EP, Leung SF, Felip E, Group E-E-EGW. Nasopharyngeal cancer: EHNS-ESMO-ESTRO Clinical Practice Guidelines for diagnosis, treatment and follow-up. Ann Onco. 2012;23(Suppl 7):vii83-5

2. Tao Q, Chan AT. Nasopharyngeal carcinoma: molecular pathogenesis and therapeutic developments. Expert Rev Mol Med. 2007;9:1-24.

3. Wei WI, Kwong DL. Current management strategy of nasopharyngeal carcinoma. Clin Exp Otorhinolaryngol. 2010;3:1-12.

4. Lee AW, Ma BB, Ng WT, Chan AT. Management of nasopharyngeal carcinoma: current practice and future perspective. J Clin Oncol. 2015;33: 3356-64.

5. Dai W, Zheng H, Cheung AK, Lung ML. Genetic and epigenetic landscape of nasopharyngeal carcinoma. Chin Clin Oncol. 2016;5:16.

6. Li LL, Shu XS, Wang ZH, Cao Y, Tao Q. Epigenetic disruption of cell signaling in nasopharyngeal carcinoma. Chin J Cancer. 2011;30:231-9.

7. Chen T, Long B, Ren G, Xiang T, Li L, Wang Z, He Y, Zeng Q, Hong S, Hu G. Protocadherin 20 acts as a tumor suppressor gene: epigenetic inactivation in nasopharyngeal carcinoma. J Cell Biochem. 2015;116:1766-75.

8. Fendri A, Khabir A, Hadri-Guiga B, Sellami-Boudawara T, Daoud J, Frikha M, Ghorbel A, Gargouri A, Mokdad-Gargouri R. Epigenetic alteration of the Wnt inhibitory factor-1 promoter is common and occurs in advanced stage of Tunisian nasopharyngeal carcinoma. Cancer Investig. 2010;28:896-903.

9. Chow LS, Lo KW, Kwong J, To KF, Tsang KS, Lam CW, Dammann R, Huang DP. RASSF1A is a target tumor suppressor from 3p21.3 in nasopharyngeal carcinoma. Int J Cancer. 2004:109:839-47.

10. Jin H, Wang $X$, Ying J, Wong AH, Li H, Lee KY, Srivastava G, Chan AT, Yeo W, Ma BB, et al. Epigenetic identification of ADAMTS18 as a novel 16q23.1 tumor suppressor frequently silenced in esophageal, nasopharyngeal and multiple other carcinomas. Oncogene. 2007;26:7490-8.

11. Cheung AK, Lung HL, Hung SC, Law EW, Cheng Y, Yau WL, Bangarusamy DK, Miller LD, Liu ET, Shao JY, et al. Functional analysis of a cell cycleassociated, tumor-suppressive gene, protein tyrosine phosphatase receptor type $\mathrm{G}$, in nasopharyngeal carcinoma. Cancer Res. 2008;68:8137-45.

12. Du C, Huang T, Sun D, Mo Y, Feng H, Zhou X, Xiao X, Yu N, Hou B, Huang $\mathrm{G}$, et al. CDH4 as a novel putative tumor suppressor gene epigenetically silenced by promoter hypermethylation in nasopharyngeal carcinoma. Cancer Lett. 2011;309:54-61.

13. Li L, Ying J, Li H, Zhang Y, Shu X, Fan Y, Tan J, Cao Y, Tsao SW, Srivastava G, et al. The human cadherin 11 is a pro-apoptotic tumor suppressor modulating cell stemness through Wnt/beta-catenin signaling and silenced in common carcinomas. Oncogene. 2012;31:3901-12.

14. Zhang S, Li S, Gao JL. Promoter methylation status of the tumor suppressor gene SOX11 is associated with cell growth and invasion in nasopharyngeal carcinoma. Cancer Cell Int. 2013;13:109.

15. Li L, Zhang Y, Fan Y, Sun K, Su X, Du Z, Tsao SW, Loh TK, Sun H, Chan AT, et al. Characterization of the nasopharyngeal carcinoma methylome identifies aberrant disruption of key signaling pathways and methylated tumor suppressor genes. Epigenomics. 2015;7:155-73.

16. Chan SL, Cui Y, van Hasselt A, Li H, Srivastava G, Jin H, Ng KM, Wang Y, Lee KY, Tsao GS, et al. The tumor suppressor Wnt inhibitory factor 1 is frequently methylated in nasopharyngeal and esophageal carcinomas. Lab Investig. 2007;87:644-50

17. Ito S, D'Alessio AC, Taranova OV, Hong K, Sowers LC, Zhang Y. Role of Tet proteins in $5 \mathrm{mC}$ to $5 \mathrm{hmC}$ conversion, ES-cell self-renewal and inner cell mass specification. Nature. 2010;466:1129-33.

18. Tahiliani M, Koh KP, Shen Y, Pastor WA, Bandukwala H, Brudno Y, Agarwal S, lyer LM, Liu DR, Aravind L, Rao A. Conversion of 5-methylcytosine to 5hydroxymethylcytosine in mammalian DNA by MLL partner TET1. Science. 2009;324:930-5. 
19. Frauer C, Rottach A, Meilinger D, Bultmann S, Fellinger K, Hasenoder S, Wang M, Qin W, Soding J, Spada F, Leonhardt H. Different binding properties and function of CXXC zinc finger domains in Dnmt1 and Tet1. PLoS One. 2011;6:e16627.

20. Mohr F, Dohner K, Buske C, Rawat VP. TET genes: new players in DNA demethylation and important determinants for stemness. Exp Hematol. 2011;39:272-81.

21. Ittel A, Jeandidier E, Helias C, Perrusson N, Humbrecht C, Lioure B, Mazurie

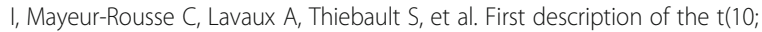
11) (q22;q23)/MLL-TET1 translocation in a T-cell lymphoblastic lymphoma, with subsequent lineage switch to acute myelomonocytic myeloid leukemia. Haematologica. 2013;98:e166-8.

22. Lorsbach RB, Moore J, Mathew S, Raimondi SC, Mukatira ST, Downing JR TET1, a member of a novel protein family, is fused to MLL in acute myeloid leukemia containing the $t(10 ; 11)$ (q22;q23). Leukemia. 2003;17:637-41.

23. Sang Y, Cheng C, Tang XF, Zhang MF, LV XB. Hypermethylation of TET1 promoter is a new diagnosic marker for breast cancer metastasis. Asian Pac J Cancer Prev. 2015;16:1197-200.

24. Neri F, Dettori D, Incarnato D, Krepelova A, Rapelli S, Maldotti M, Parlato C, Paliogiannis $\mathrm{P}$, Oliviero S. TET1 is a tumour suppressor that inhibits colon cancer growth by derepressing inhibitors of the WNT pathway. Oncogene. 2015;34:4168-76.

25. Fu HL, Ma Y, Lu LG, Hou P, Li BJ, Jin WL, Cui DX. TET1 exerts its tumor suppressor function by interacting with $\mathrm{p} 53-\mathrm{EZH} 2$ pathway in gastric cancer. J Biomed Nanotechnol. 2014;10:1217-30.

26. Hsu CH, Peng KL, Kang ML, Chen YR, Yang YC, Tsai CH, Chu CS, Jeng YM, Chen YT, Lin FM, et al. TET1 suppresses cancer invasion by activating the tissue inhibitors of metalloproteinases. Cell Rep. 2012;2:568-79.

27. Lin LL, Wang W, Hu Z, Wang LW, Chang J, Qian H. Negative feedback of miR29 family TET1 involves in hepatocellular cancer. Med Oncol. 2014;31:291.

28. Fan M, He X, Xu X. Restored expression levels of TET1 decrease the proliferation and migration of renal carcinoma cells. Mol Med Rep. 2015; 12:4837-42.

29. Li L, Li C, Mao H, Du Z, Chan WY, Murray P, Luo B, Chan AT, Mok TS, Chan FK, et al. Epigenetic inactivation of the CPG demethylase TET1 as a DNA methylation feedback loop in human cancers. Sci Rep. 2016;6:26591.

30. Xiang T, Li L, Fan Y, Jiang Y, Ying Y, Putti TC, Tao Q, Ren G. PLCD1 is a functional tumor suppressor inducing $\mathrm{G}(2) / \mathrm{M}$ arrest and frequently methylated in breast cancer. Cancer Biol Ther. 2010;10:520-7.

31. Li L, Xu J, Qiu G, Ying J, Du Z, Xiang T, Wong KY, Srivastava G, Zhu XF, Mok TS, et al. Epigenomic characterization of a p53-regulated 3p22.2 tumor suppressor that inhibits STAT3 phosphorylation via protein docking and is frequently methylated in esophageal and other carcinomas. Theranostics. 2018:8:61-77.

32. Tao Q, Huang H, Geiman TM, Lim CY, Fu L, Qiu GH, Robertson KD. Defective de novo methylation of viral and cellular DNA sequences in ICF syndrome cells. Hum Mol Genet. 2002;11:2091-102.

33. Tao Q, Swinnen LJ, Yang J, Srivastava G, Robertson KD, Ambinder RF. Methylation status of the Epstein-Barr virus major latent promoter $\mathrm{C}$ in iatrogenic B cell lymphoproliferative disease. Application of PCR-based analysis. Am J Pathol. 1999;155:619-25.

34. Li L, Ying J, Tong X, Zhong L, Su X, Xiang T, Shu X, Rong R, Xiong L, Li H, et al. Epigenetic identification of receptor tyrosine kinase-like orphan receptor 2 as a functional tumor suppressor inhibiting beta-catenin and AKT signaling but frequently methylated in common carcinomas. Cell Mol Life Sci. 2014;71:2179-92.

35. Pan X, Zhou T, Tai YH, Wang C, Zhao J, Cao Y, Chen Y, Zhang PJ, Yu M, Zhen $C$, et al. Elevated expression of CUEDC2 protein confers endocrine resistance in breast cancer. Nat Med. 2011;17:708-14.

36. Zhang Y, Fan J, Fan Y, Li L, He X, Xiang Q, Mu J, Zhou D, Sun X, Yang Y, et al. The new $6 q 27$ tumor suppressor DACT2, frequently silenced by CpG methylation, sensitizes nasopharyngeal cancer cells to paclitaxel and 5-FU toxicity via $\beta$-catenin/Cdc25c signaling and G2/M arrest. Clin Epigenetics. 2018;10:26.

37. Lu HG, Zhan W, Yan L, Qin RY, Yan YP, Yang ZJ, Liu GC, Li GQ, Wang HF, Li $\mathrm{XL}$, et al. TET1 partially mediates HDAC inhibitor-induced suppression of breast cancer invasion. Mol Med Rep. 2014;10:2595-600.

38. Yokoyama S, Higashi M, Tsutsumida H, Wakimoto J, Hamada T, Wiest E, Matsuo K, Kitazono I, Goto Y, Guo X, et al. TET1-mediated DNA hypomethylation regulates the expression of MUC4 in lung cancer. Genes Cancer. 2017:8:517-27.
39. Ren XY, Zhou GQ, Jiang W, Sun Y, Xu YF, Li YQ, Tang XR, Wen X, He QM, Yang XJ, et al. Low SFRP1 expression correlates with poor prognosis and promotes cell invasion by activating the Wnt/beta-catenin signaling pathway in NPC. Cancer Prev Res (Phila). 2015;8:968-77.

40. Wong AM, Kong KL, Chen L, Liu M, Zhu C, Tsang JW, Guan XY. Characterization of CACNA2D3 as a putative tumor suppressor gene in the development and progression of nasopharyngeal carcinoma. Int J Cancer. 2013;133:2284-95.

41. Chen Z, Tang C, Zhu Y, Xie M, He D, Pan Q, Zhang P, Hua D, Wang T, Jin L, et al. TrpC5 regulates differentiation through the Ca2+/Wnt5a signalling pathway in colorectal cancer. Clin Sci (Lond). 2017;131:227-37.

42. Pei YF, Tao R, Li JF, Su LP, Yu BQ, Wu XY, Yan M, Gu QL, Zhu ZG, Liu BY. TET1 inhibits gastric cancer growth and metastasis by PTEN demethylation and re-expression. Oncotarget. 2016;7:31322-35.

43. Voorham QJ, Janssen J, Tijssen M, Snellenberg S, Mongera S, van Grieken NC, Grabsch H, Kliment M, Rembacken BJ, Mulder CJ, et al. Promoter methylation of Wnt-antagonists in polypoid and nonpolypoid colorectal adenomas. BMC Cancer. 2013;13:603.

44. Rawson JB, Manno M, Mrkonjic M, Daftary D, Dicks E, Buchanan DD, Younghusband HB, Parfrey PS, Young JP, Pollett A, et al. Promoter methylation of Wnt antagonists DKK1 and SFRP1 is associated with opposing tumor subtypes in two large populations of colorectal cancer patients. Carcinogenesis. 2011;32:741-7.

45. Ying Y, Tao Q. Epigenetic disruption of the WNT/beta-catenin signaling pathway in human cancers. Epigenetics. 2009;4:307-12.

46. Duan H, Yan Z, Chen W, Wu Y, Han J, Guo H, Qiao J. TET1 inhibits EMT of ovarian cancer cells through activating Wnt/beta-catenin signaling inhibitors DKK1 and SFRP2. Gynecol Oncol. 2017;147:408-17.

47. Asem MS, Buechler S, Wates RB, Miller DL, Stack MS. Wnt5a signaling in cancer. Cancers (Basel). 2016;8:79.

48. Yap LF, Ahmad M, Zabidi MM, Chu TL, Chai SJ, Lee HM, Lim PV, Wei W, Dawson C, Teo SH, Khoo AS. Oncogenic effects of WNT5A in Epstein-Barr virus-associated nasopharyngeal carcinoma. Int J Oncol. 2014:44:1774-80.

49. Zhu N, Qin L, Luo Z, Guo Q, Yang L, Liao D. Challenging role of Wnt5a and its signaling pathway in cancer metastasis (Review). Exp Ther Med. 2014;8:3-8.

50. Qin L, Yin YT, Zheng FJ, Peng LX, Yang CF, Bao YN, Liang YY, Li XJ, Xiang $Y Q$, Sun $R$, et al. WNT5A promotes stemness characteristics in nasopharyngeal carcinoma cells leading to metastasis and tumorigenesis. Oncotarget. 2015;6:10239-52

51. Zhong Z, Shan M, Wang J, Liu T, Shi Q, Pang D. Decreased Wnt5a expression is a poor prognostic factor in triple-negative breast cancer. Med Sci Monit. 2016;22:1-7.

52. Mehdawi LM, Prasad CP, Ehrnstrom R, Andersson T, Sjolander A. Noncanonical WNT5A signaling up-regulates the expression of the tumor suppressor 15-PGDH and induces differentiation of colon cancer cells. Mol Oncol. 2016:10:1415-29.

53. Zhang Y, Du J, Zheng J, Liu J, Xu R, Shen T, Zhu Y, Chang J, Wang H, Zhang Z, et al. EGF-reduced Wnt5a transcription induces epithelial-mesenchymal transition via Arf6-ERK signaling in gastric cancer cells. Oncotarget. 2015:6:7244-61.

54. Thiele S, Gobel A, Rachner TD, Fuessel S, Froehner M, Muders MH, Baretton GB, Bernhardt R, Jakob F, Gluer CC, et al. WNT5A has anti-prostate cancer effects in vitro and reduces tumor growth in the skeleton in vivo. J Bone Miner Res. 2015;30:471-80.

55. Huang TC, Lee PT, Wu MH, Huang CC, Ko CY, Lee YC, Lin DY, Cheng YW, Lee $\mathrm{KH}$. Distinct roles and differential expression levels of Wnt5a mRNA isoforms in colorectal cancer cells. PLoS One. 2017:12:e0181034.

\section{Ready to submit your research? Choose BMC and benefit from:}

- fast, convenient online submission

- thorough peer review by experienced researchers in your field

- rapid publication on acceptance

- support for research data, including large and complex data types

- gold Open Access which fosters wider collaboration and increased citations

- maximum visibility for your research: over $100 \mathrm{M}$ website views per year

At $\mathrm{BMC}$, research is always in progress.

Learn more biomedcentral.com/submissions 